\title{
Structural and Corresponding Magnetic Properties of Sputtered Ni/Al Multilayer Films: Effect of Ni Layer Thickness
}

\author{
A. KARPuZ ${ }^{a *}$, H. KÖÇKAR ${ }^{b}$ AND S. ÇÖLMEKÇi் ${ }^{b}$ \\ ${ }^{a}$ Department of Physics, Kamil Ozdag Science Faculty, Karamanoglu Mehmetbey University, Karaman, Turkey \\ ${ }^{b}$ Department of Physics, Science and Literat. Faculty, Balikesir University, Balikesir, Turkey
}

(Received April 25, 2018; revised version July 24, 2018; in final form August 21, 2018)

A series of Ni/Al multilayers with different thicknesses of Ni layers was produced by a sputtering technique. The deposition parameters of optimum magnetic properties for write heads were detected by scanning the magnetic layer thickness from 0 to $70 \mathrm{~nm}$. The optimum magnetic properties were decided by obtaining the saturation magnetization, $M_{s}$, coercivity, $H_{c}$ and $M_{s} / H_{c}$ ratios from the hysteresis loops. A face centered cubic (fcc) structure was established for all films. Transition surface morphology; i.e., a surface morphology between an apical + uneven structure (observed for the mono layered Al film) and an acicular + relatively smooth structure (observed for the films with Ni layer thicknesses of $30 \mathrm{~nm}$ and $70 \mathrm{~nm}$ ) occurred on the surface of the film with Ni layer thickness of $10 \mathrm{~nm}$. This transition surface morphology was very similar to that of the substrate as compared to the other morphologies and it may lead to relatively lower $H_{c}$ value. A significant increase in $H_{c}$ value was detected for $\mathrm{Ni} / \mathrm{Al}$ film with Ni layer thickness of $70 \mathrm{~nm}$. The increase was attributed to the irregular acicular morphology of substrate and high crystallite size of $\mathrm{Al}$ fcc (111). The deposition parameters of $8[\mathrm{Ni}(10 \mathrm{~nm}) / \mathrm{Al}(10 \mathrm{~nm})]$ multilayer can be considered in order to support the higher $M_{s} / H_{c}$ ratio which has a key role for effective technological applications of write heads.

DOI: 10.12693/APhysPolA.134.1180

PACS/topics: layer thickness, magnetic properties, $\mathrm{Ni} / \mathrm{Al}$ multilayers, sputtering system

\section{Introduction}

Several types of magnetic materials, including alloys [1], multilayer films [2] and multilayer nanowires $[3,4]$, have been used in a lot of studies in recent years. There are a lot of advantages in focusing on magnetic thin films since their applications are rapidly expanding in technology [5]. $\mathrm{Ni} / \mathrm{Al}$ is a very useful magnetic multilayer and it has also been used by various researchers in several studies. For example, Kuk et al. [6] recently studied the effect of $\mathrm{Al} / \mathrm{Ni}$ atomic ratio on $\mathrm{Al} / \mathrm{Ni}$ multilayers and Noro et al. [7] investigated the intermetallic phase formation in $\mathrm{Ni} / \mathrm{Al}$ multilayers. Besides, Simões et al. [8] focused on the anisothermal solid-state reactions for $\mathrm{Ni} / \mathrm{Al}$ multilayer thin films while Tixier et al. [9] were interested in the relation of indentation hardness measurements of $\mathrm{Ni}_{3} \mathrm{Al} / \mathrm{Ni}$ multilayers with the structural properties of the layers. In addition, Kang et al. [10] reported the phenomenon of magnetic anisotropy for $\mathrm{Ni} / \mathrm{A} 1$ multilayers prepared by a sputtering technique. However, the limited number of studies on magnetic hysteresis loop properties of sputtered $\mathrm{Ni} / \mathrm{Al}$ multilayers is obvious in literature.

The magnetic properties of a film take over an important position in data storage and in the relevant areas [11]. In general, saturation magnetization, $M_{s}$, remanent magnetization and coercivity, $H_{c}$ are the main

\footnotetext{
*corresponding author; e-mail: alikarpuz@kmu.edu.tr
}

magnetic properties which disclose the characteristics of a magnetic material $[12,13]$. The soft magnetic materials which have the low $H_{c}$ values are the unique components for the important devices, for example, motors, relays and transformers [14]. In addition, the high $M_{s}$ values are necessary to reduce their dimensions and obtain effective small devices [15]. The magnetic materials with high $M_{s}$ and low $H_{c}$ are very promising for the magnetic technology [16], especially for write heads $[17,18]$. This magnetic condition is also valid for devices which contain a typical electromagnet [14]. These magnetic properties can be easily adjusted according to intended scope since they are mainly affected by various effects in a film such as a change in crystalline structure [19, 20]. The crystalline structure can be considerably changed by changing production parameters during the film deposition. The sputtering technique is one of the many deposition techniques which have adjustable production parameters affecting the structural properties of a film. It is often used to produce thin or ultra thin films of high quality [21].

In this study, the effect of different thicknesses of magnetic layers on the structural and magnetic hysteresis loop properties of $\mathrm{Ni} / \mathrm{Al}$ multilayer films was studied and the deposition parameters of optimum magnetic properties for write head materials in a hard disk drive were determined by investigating $M_{s} / H_{c}$ ratios obtained from the magnetic hysteresis loops of the films. Besides, despite the limited number of studies on properties of sputtered $\mathrm{Ni} / \mathrm{Al}$ multilayers, this study compares the obtained results with those of literature. 


\section{Experimental details}

A series of $\mathrm{Ni} / \mathrm{Al}$ multilayer films was produced by a sputtering technique from high purity commercial $\mathrm{Ni}$ and $\mathrm{Al}$ targets located onto the DC magnetrons. The deposition was achieved on the commercial acetate substrates $(4.5 \mathrm{~cm} \times 2.5 \mathrm{~cm})$ at room temperature (around $25^{\circ} \mathrm{C}$ ). The substrate temperature varied by $\pm 5^{\circ} \mathrm{C}$ because of the sputtering process during the film production. The substrate was far from the targets by about $12.5 \mathrm{~cm}$. The lowest pressure value of the chamber was $5 \times 10^{-5} \mathrm{mbar}$ and it increased to around $5 \times 10^{-3}$ mbar during the sputtering process due to sending of argon into the chamber. The thickness measurements of each layer were based on a quartz crystal microbalance thickness monitor. Total film thickness and the thickness of each Al layer were adjusted as $160 \mathrm{~nm}$ and $10 \mathrm{~nm}$, respectively. On the other hand, the thickness of $\mathrm{Ni}$ layers was changed gradually as $0,10,30$, and $70 \mathrm{~nm}$ to investigate the effect of different thicknesses of $\mathrm{Ni}$ layers on the properties of multilayers. For better understanding, schematic illustrations of the sputtered multilayers of $8[\mathrm{Ni}(10 \mathrm{~nm}) / \mathrm{Al}(10 \mathrm{~nm})]$ and $4[\mathrm{Ni}(30 \mathrm{~nm}) / \mathrm{Al}(10 \mathrm{~nm})]$ are given in Fig. 1a and $\mathrm{b}$, respectively. The deposition rates of $\mathrm{Ni}$ and $\mathrm{Al}$ were

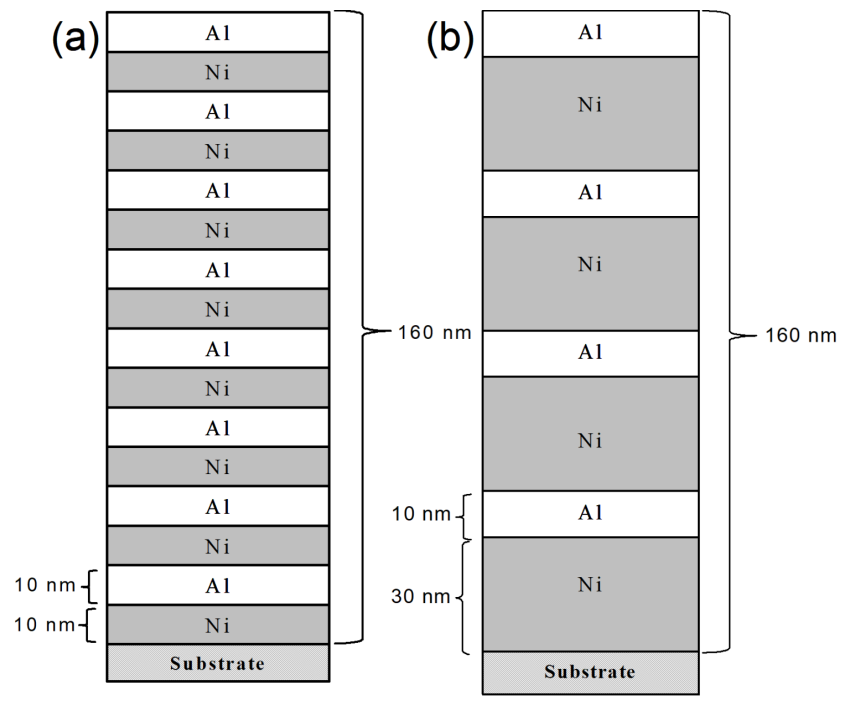

Fig. 1. Schematic illustrations of the sputtered multilayers: (a) $8[\mathrm{Ni}(10 \mathrm{~nm}) / \mathrm{Al}(10 \mathrm{~nm})]$, (b) $4[\mathrm{Ni}(30 \mathrm{~nm})$ $/ \mathrm{Al}(10 \mathrm{~nm})]$ kept constant as $0.05 \mathrm{~nm} / \mathrm{s}$ for all productions. For all multilayers, a Ni layer was firstly sputtered onto the substrate and then, an $\mathrm{Al}$ layer $(10 \mathrm{~nm})$ was deposited onto this Ni layer. This procedure was repeated until obtaining the total film thickness $(160 \mathrm{~nm})$. The compositional analysis was done using an energy dispersive X-ray spectroscopy (EDX, BRUKER) during the surface monitoring carried out by a scanning electron microscope (SEM, ZEISS EVO LS 10). The crystal structure analysis was performed by using an X-ray diffractometer (BRUKER) with the X-ray diffraction (XRD) technique. The Bragg angle was scanned between $30^{\circ}$ and $100^{\circ}$ and the $\mathrm{Cu} K_{\alpha}$ radiation was used to obtain the XRD patterns of the multilayers. In addition, the surface monitoring was improved with the images of the atomic force microscope (AFM, NanoMagnetics Instruments). Hysteresis loops of the multilayers were obtained with a vibrating sample magnetometer (VSM, ADE TECHNOLOGIES DMSEV9) by sending the magnetic field parallel to the film plane. The measurements were achieved at room temperature by creating the magnetic field intensity of $20 \mathrm{kOe}$ and scanning its intensity between $\pm 20 \mathrm{kOe}$. The $M_{s}$ values were detected by considering the complete volume of each film.

\section{Results and discussion}

The data from elemental analysis show that the films that have Ni layer thickness of $0,10,30$, and $70 \mathrm{~nm}$ contain $0 \%, 39 \%, 61 \%$, and $75 \% \mathrm{Ni}$ atoms, respectively, as shown in Table I. According to the results, the $\mathrm{Ni}$ content in the films gradually increased with the increasing thickness of $\mathrm{Ni}$ layers. Also, it was detected that the rest of the films include only $\mathrm{Al}$ atoms. Although the films have a multilayered structure, the indicated atomic contents are total quantities of $\mathrm{Ni}$ or $\mathrm{Al}$ atoms in the investigated $\mathrm{Ni} / \mathrm{Al}$ films. The crystalline structure analysis done by XRD shows that the all films are in the face centered cubic (fcc) form. The XRD patterns of the films are shown in Fig. 2. Some differences were observed in the peaks of the diffraction patterns with the change of magnetic layers thickness. Namely, the intensity of Al fcc (111) peak which occurred at around $38^{\circ}$ Bragg angle decreased gradually as the thickness of Ni layers increased (see Fig. 2).

Analysis data of $\mathrm{Ni} / \mathrm{Al}$ multilayers sputtered by considering different thicknesses of Ni layers

TABLE I

\begin{tabular}{|c|c|c|c|c|c|c|c|c|c|}
\hline \multirow{3}{*}{ Multilayer } & \multirow{3}{*}{$\begin{array}{c}\text { Parameter } \\
\text { Ni thickness } \\
{[\mathrm{nm}]}\end{array}$} & \multicolumn{2}{|c|}{ EDX } & \multirow{2}{*}{\multicolumn{2}{|c|}{$\begin{array}{c}\text { XRD } \\
\text { Crystallite size }[\mathrm{nm}]\end{array}$}} & \multicolumn{2}{|c|}{ AFM } & \multicolumn{2}{|c|}{ VSM } \\
\hline & & $\mathrm{Ni}$ & $\mathrm{Al}$ & & & $R_{a}$ & $R_{q}$ & $M_{s}$ & $H_{c}$ \\
\hline & & \multicolumn{2}{|c|}{$[\text { at. } \%]^{*}$} & at $38^{\circ}$ & at $45^{\circ}$ & \multicolumn{2}{|c|}{$[\mathrm{nm}]$} & {$\left[\mathrm{emu} / \mathrm{cm}^{3}\right]$} & [Oe] \\
\hline $1[\mathrm{Ni}(0 \mathrm{~nm}) / \operatorname{Al}(160 \mathrm{~nm})]=160 \mathrm{~nm}$ & 0 & 0 & 100 & - & - & 36 & 45 & - & - \\
\hline $8[\mathrm{Ni}(10 \mathrm{~nm}) / \operatorname{Al}(10 \mathrm{~nm})]=160 \mathrm{~nm}$ & 10 & 39 & 61 & 27 & 14 & 46 & 56 & 272 & 30 \\
\hline $4[\mathrm{Ni}(30 \mathrm{~nm}) / \operatorname{Al}(10 \mathrm{~nm})]=160 \mathrm{~nm}$ & 30 & 61 & 39 & 30 & 13 & 13 & 16 & 451 & 89 \\
\hline $2[\mathrm{Ni}(70 \mathrm{~nm}) / \operatorname{Al}(10 \mathrm{~nm})]=160 \mathrm{~nm}$ & 70 & 75 & 25 & 38 & 12 & 15 & 18 & 503 & 201 \\
\hline
\end{tabular}

at $38^{\circ}: \mathrm{Al}$ fcc (111), at $45^{\circ}: \mathrm{Ni}$ fcc (111) $+\mathrm{Al}$ fcc (200)

*indicates the total quantities of $\mathrm{Ni}$ or $\mathrm{Al}$ atoms in the investigated $\mathrm{Ni} / \mathrm{Al}$ multilayers 


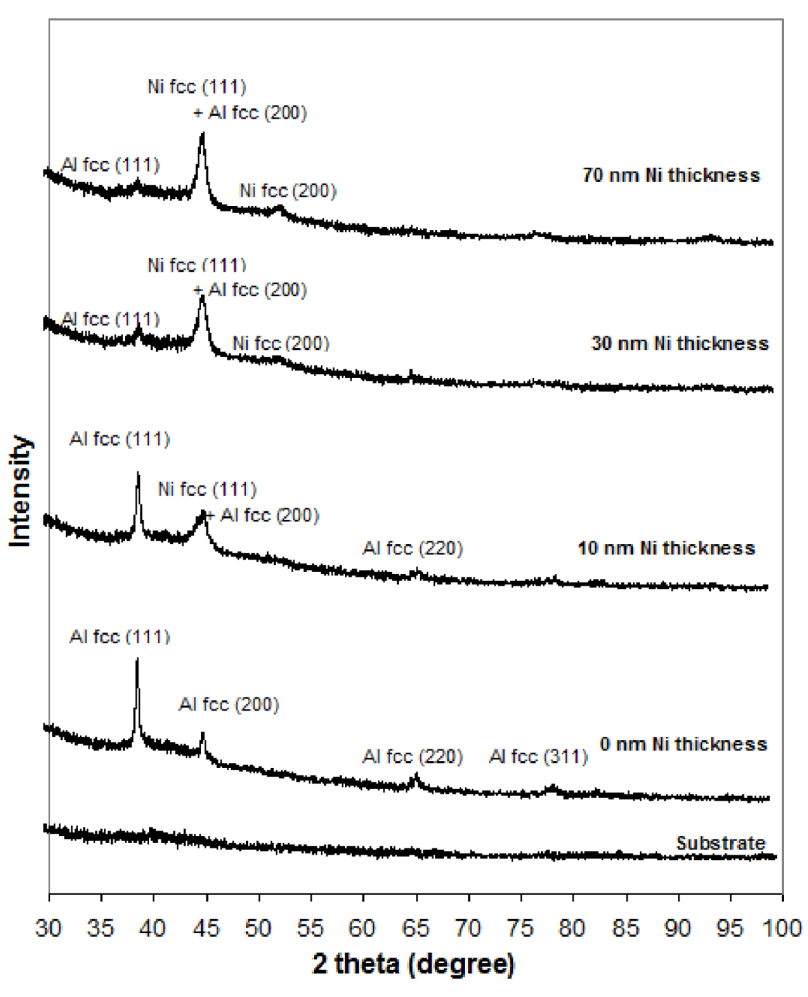

Fig. 2. XRD patterns of $\mathrm{Ni} / \mathrm{Al}$ multilayers deposited by considering different thicknesses of Ni layers.

The XRD pattern of multilayer with $10 \mathrm{~nm}$ Ni thickness has the highest peak intensity of fcc (111) plane of $\mathrm{Al}$ among the $\mathrm{Ni} / \mathrm{Al}$ multilayers. Also, the intensities of the (220) and (311) peaks decreased with the increase of $\mathrm{Ni}$ layer thickness and hence $\mathrm{Ni}$ content in the films and they disappeared from the patterns of the films with $30 \mathrm{~nm}$ and $70 \mathrm{~nm} \mathrm{Ni}$ layer thickness. Beside these peaks, there is one more peak located at around $45^{\circ}$ Bragg angle and its intensity increases with the increase of Ni content. Since this peak already exists at the XRD pattern of the pure $\mathrm{Al}$ film and its intensity increases with the increasing $\mathrm{Ni}$ content, it was assumed as Ni fcc (111) + Al fcc (200). In other words, this peak was labelled as a mixture of (111) and (200) planes of fcc structure for $\mathrm{Ni}$ and $\mathrm{Al}$, respectively. The peaks observed at around $38^{\circ}$ and $45^{\circ}$ in the XRD patterns of the $\mathrm{Ni} / \mathrm{Al}$ multilayers investigated in the present study were also observed in the XRD pattern of the as-deposited $5[\mathrm{Ni}(200 \AA) /(\mathrm{Al}(100 \AA)]$ multilayer investigated in [22] as $\mathrm{Al}(111)$ and $\mathrm{Ni}(111) / \mathrm{Al}(200)$, respectively. The main peak was the latter. On the other hand, $\mathrm{Ni}$ (222) reflection observed at around $98^{\circ}$ Bragg angle in the XRD pattern of the multilayer in study [22] was not observed in this study. Besides, the peaks observed at around $38^{\circ}$ and $45^{\circ}$ were also detected in the XRD pattern of the as-deposited Al-rich multilayer, $5[\mathrm{Ni}(50 \AA) /(\mathrm{Al}(227 \AA)]$, investigated in study [22]. For Al-rich multilayer in [22], the main peak was Al (111) as observed for the $8[\mathrm{Ni}(10 \mathrm{~nm}) / \mathrm{Al}(10 \mathrm{~nm})]$ multilayer investigated in this study. This can be attributed to Al-rich content of the multilayers (see Table I). In a study [23] aimed to investigate the XRD results in situ heating of large period $\mathrm{Ni} / \mathrm{Al}$ multilayer, a strong peak was detected at $\approx 44^{\circ}$ Bragg angle of XRD pattern of "as-deposited" $\mathrm{Ni} / \mathrm{Al}$ multilayers corresponding to the (111) plane for solid solution of $\mathrm{Ni}(\mathrm{Al})$. For XRD results, some differences were reported between a study [10] done by Kang et al. and the present study. It was found in study [10] that $\mathrm{Ni}(25 \AA) / \mathrm{Al}(35 \AA)$ multilayer has only Ni (111) peak at around $44^{\circ}$ angle. On the other hand, the characteristic (200) peak of the fcc structure that occurred at around $51^{\circ}$ Bragg angle was marked as a plane of $\mathrm{Ni}$ according to JCPDS card for Ni numbered as 04-0850. The diffraction pattern of the substrates was also given in Fig. 2 and it was understood that any crystalline formation was not obtained, unlike those of the films investigated. The crystallite size of each observed plane in the XRD patterns of multilayer structure was also calculated by the Scherrer equation, as given in [24]. The crystallite sizes were calculated for two considerable peaks in the XRD patterns of the multilayer systems. It was found that the sizes of Al fcc (111) crystallites are 27, 30, and $38 \mathrm{~nm}$, and the sizes of Ni fcc (111) + Al fcc (200) crystallites are 14, 13, and $12 \mathrm{~nm}$ for the multilayers with 10, 30, and $70 \mathrm{~nm}$ $\mathrm{Ni}$ layer thicknesses, respectively. The values are also listed in Table I. The crystallite size of Ni fcc (111) + Al fcc (200) slightly decreased, whereas that of Al fcc (111) crystallite increased as the Ni layers thickness increased. In addition, it can be assumed that (111) preferential texture of the pure $\mathrm{Al}$ film exists for the $\mathrm{Ni} / \mathrm{Al}$ multilayers sputtered with different thicknesses of Ni layers because the intensity of $\mathrm{Ni}$ fcc (111) component of overlapped peaks detected at around $45^{\circ}$ Bragg angle is expected to increase as the thickness of Ni layers increases. Furthermore, the XRD pattern given in [25] for as-deposited $\mathrm{Ni}-25$ at.\% $\mathrm{Al}$ at room temperature shows some similarities to that of the $\mathrm{Ni} / \mathrm{Al}$ multilayer has $\mathrm{Ni}$ layer thickness of $70 \mathrm{~nm}(75$ at. $\% \mathrm{Ni} / 25$ at. $\% \mathrm{Al})$ investigated in this study, especially concerning the overlapped peaks formed at around $45^{\circ}$. However, there is no any peak formation at around $51^{\circ}$ Bragg angle in the XRD pattern shown in [25] for as-deposited $\mathrm{Ni}-25$ at.\% $\mathrm{Al}$ at room temperature, unlike the present study. This may arise from multilayered structure of the investigated films.

Figure 3 shows the SEM images of the films produced with different thicknesses of Ni layers. It is obviously shown from Fig. 3a that the surface of the pure Al film produced as a mono layered structure, unlike the other films, is covered with a lot of grains having around $200 \mathrm{~nm}$ diameters. These grains disperse almost homogeneously onto the film surface. The other parts of Fig. 3 illustrate the SEM images of the multilayer films investigated according to different thicknesses of magnetic layers. It was shown that these surface morphologies are in almost similar form. In other words, the surface morphology observed with SEM is independent of change in the thickness of Ni layers. In addition, few clustered regions on the surface of the film with $\mathrm{Ni}$ layer thickness of $30 \mathrm{~nm}$ did not change this general situation of the surface morphology (see Fig. 3c). 

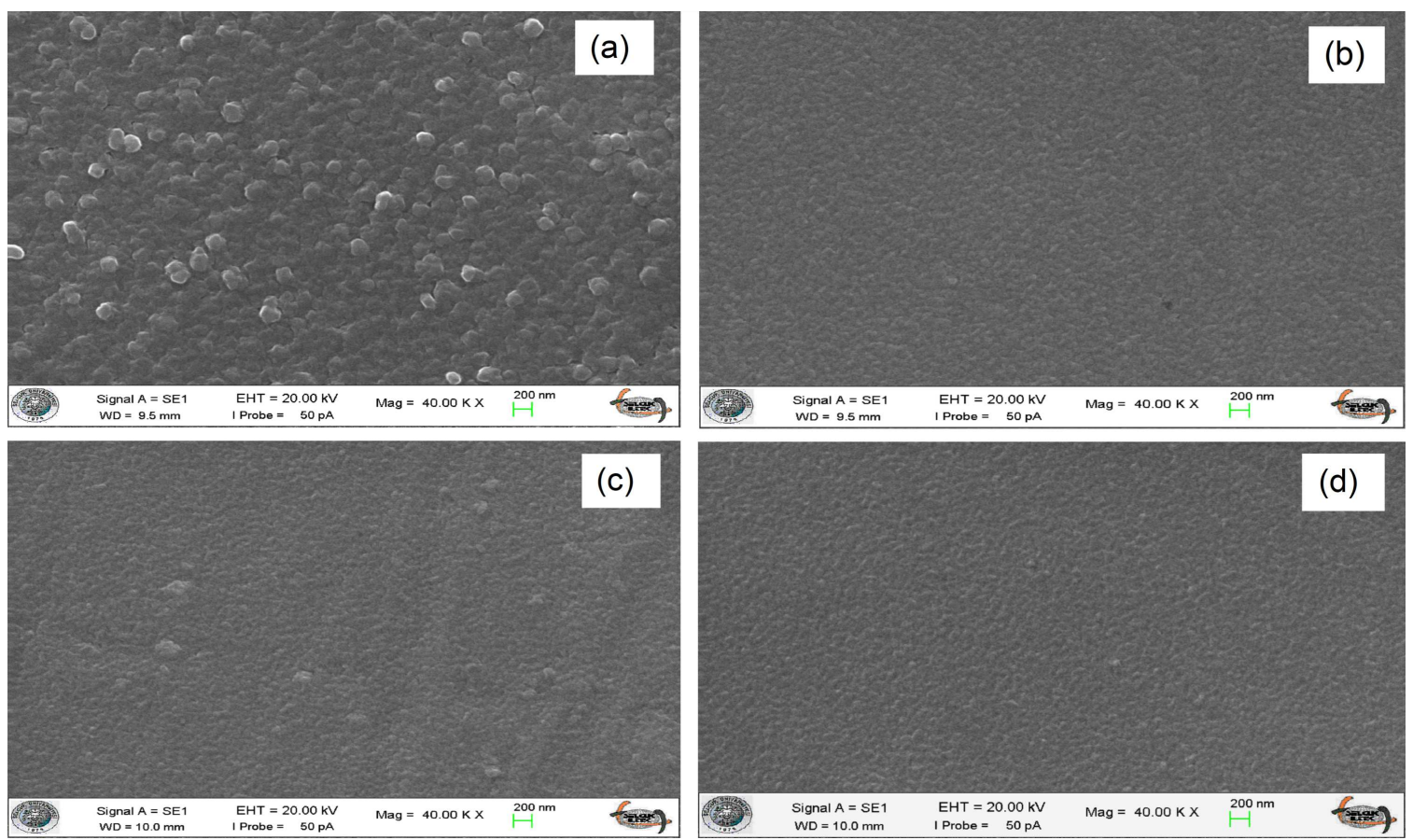

Fig. 3. SEM images of the films produced considering different thicknesses of Ni layers: (a) $0 \mathrm{~nm}$ (pure $\mathrm{Al}$ film), (b) $10 \mathrm{~nm}$, (c) $30 \mathrm{~nm}$, (d) $70 \mathrm{~nm}$.

This may be attributed to some inconsiderable experimental errors arising from different deposition processes. The surface of $\mathrm{Ni} / \mathrm{Al}$ film $(1 \mathrm{~nm} \mathrm{Ni}$ and $6 \mathrm{~nm} \mathrm{Al}$ ), asdeposited and after heating to $800^{\circ} \mathrm{C}$, was also examined by using SEM in study [26] reporting the effect of the $\mathrm{Ni} / \mathrm{Al}$ bilayer film thickness on the density of the single-walled carbon nanotubes. It was expressed that the surface morphology of the as-deposited multilayer was generally featureless. However, some clusters were formed on the surface of the heated $\mathrm{Ni} / \mathrm{Al}$ multilayer. It can be deduced that the surface morphology of the heated $\mathrm{Ni} / \mathrm{Al}$ multilayer in [26] is more similar to those of the present study than the as deposited one, although an oxidized Si substrate was used, unlike the present study.

AFM images of the films were investigated and given in Fig. 4 together with that of the substrate used. AFM image observed for mono layered $\mathrm{Al}$ film is shown in Fig. 4a. This surface has a great number of separate apical and uneven regions. The regions can be clearly distinguished because of their relatively light colors which indicate relatively high points in the AFM images. Therefore, the surface of this film can be described as a relatively rough surface. The surface morphology started to change when the $\mathrm{Ni}$ layer thickness was adjusted as $10 \mathrm{~nm}$. The surface became moderate about separate regions, whereas the rough surface existed (see Fig. 4b) for the compositions of 39 at.\% Ni and 61 at.\% Al. This type of surface can be assumed as a transition formation from an apical and uneven structure to an acicular morphology as seen in Fig. 4c and d. On the other hand, this transition morphology has a considerable region with relatively high altitude and the size of this region is about $2 \mu \mathrm{m}$ (see Fig. 4b). This formation can be attributed to the irregular structure which was called as transition morphology. An acicular surface morphology was observed for the $\mathrm{Ni} / \mathrm{Al}$ multilayers which have $\mathrm{Ni}$ layers thicknesses of $30 \mathrm{~nm}$ and $70 \mathrm{~nm}$, as shown from Fig. 4c and d. The observed acicular morphologies are of vertical type in this study. Similar acicular morphologies were also observed on the surface of as-deposited $\mathrm{Ni} / \mathrm{Al}$ multilayers examined in study [22] although they have different thickness value from those of the multilayers investigated in this study. Roughness parameters, $R_{a}$ and $R_{q}$ (root mean square), were also calculated during the AFM observation. $R_{a}$ values are $36,46,13$, and $15 \mathrm{~nm}$, while $R_{q}$ values are $45,56,16$, and $18 \mathrm{~nm}$ for the surfaces of the films with Ni layer thickness of $0,10,30$, and $70 \mathrm{~nm}$, respectively. It was understood that the considerable region with relatively high altitude observed on the surface of multilayer with Ni layer thickness of $10 \mathrm{~nm}$ caused an increase in $R_{a}$ and $R_{q}$ values. In addition, the acicular morphologies observed on the surfaces of films with $30 \mathrm{~nm}$ and $70 \mathrm{~nm}$ Ni layers thicknesses have relatively a smooth structure according to roughness parameters. However, the acicular morphology observed on the surface of the film with $\mathrm{Ni}$ layer thickness of $30 \mathrm{~nm}$ is more homogeneous than that of the film with Ni layer thickness of $70 \mathrm{~nm}$. This can be clearly seen from local regions with different altitudes in AFM images of the film with $\mathrm{Ni}$ layers thickness of $70 \mathrm{~nm}$. In other words, some considerable regions of acicular morphology on the surface of the film with Ni layer thickness of $70 \mathrm{~nm}$ have higher altitude than the rest regions (see Fig. 4d). 

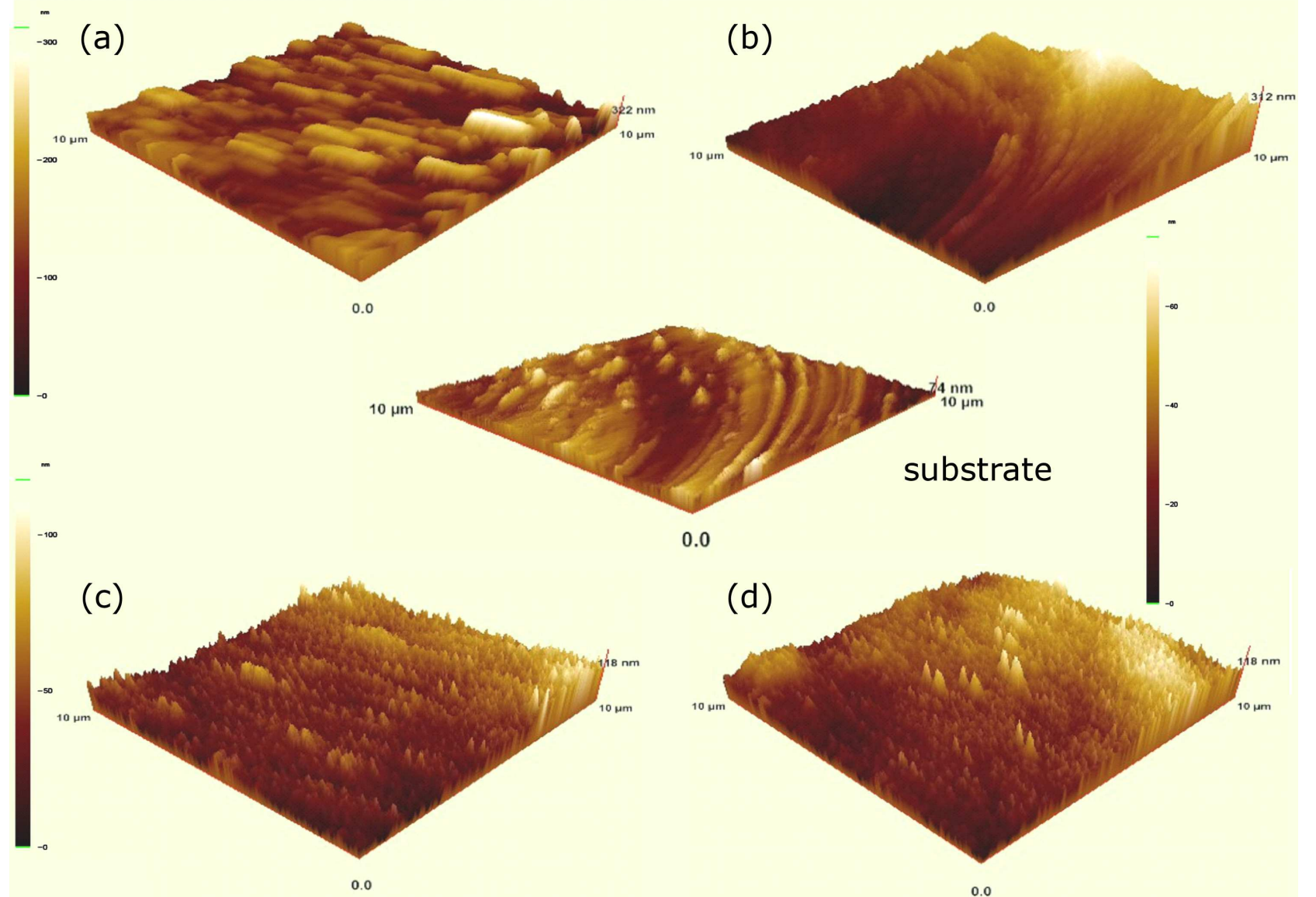

Fig. 4. AFM images of the $\mathrm{Ni} / \mathrm{Al}$ multilayers having different thicknesses of Ni layers: (a) $0 \mathrm{~nm}$ (pure $\mathrm{Al}$ film), (b) $10 \mathrm{~nm}$, (c) $30 \mathrm{~nm}$, (d) $70 \mathrm{~nm}$ and AFM image for the substrate which was used for deposition.

It was concluded that the surface morphology transformed from a structure with apical and uneven clumps to an acicular and relatively smooth morphology when the thickness of Ni layers was gradually increased from $0 \mathrm{~nm}$ to $70 \mathrm{~nm}$. Also, magnetic layer thickness has a significant role on the film surface and acicular morphology becomes highly irregular when the thickness of $\mathrm{Ni}$ layers increases from $30 \mathrm{~nm}$ to $70 \mathrm{~nm}$. A different type of irregularity in the acicular morphology was also seen in study [22]. A more homogeneous and regular acicular surface morphology was detected for as-deposited Al-rich multilayer than that of the other as-deposited multilayer examined in [22]. Besides, the surface of the substrate was also examined by AFM for better investigation of the film surfaces and its image was also given in Fig. 4. It is clearly shown from its color scale that the substrate surface is clear and smooth in comparison with those of the investigated films. It can be also emphasized that the surface morphology of $8[\mathrm{Ni}(10 \mathrm{~nm}) / \mathrm{Al}(10 \mathrm{~nm})]$ multilayer is the most similar to that of the substrate.

Magnetic behavior was revealed by measuring $M_{s}$ and $H_{c}$ values for all $\mathrm{Ni} / \mathrm{Al}$ multilayers. The hysteresis curves of the films were plotted in Fig. 5. As shown from the figure, pure $\mathrm{Al}$ film does not have any hysteresis and this is an expected situation since it is a non-magnetic ma- terial. On the other hand, the $M_{s}$ values were 272,451 , and $503 \mathrm{emu} / \mathrm{cm}^{3}$ for the films with Ni layer thicknesses of $10,30,70 \mathrm{~nm}$, respectively. The values are proportional to the atomic Ni contents in the films. $M_{s}$ value increases with increasing $\mathrm{Ni}$ content as shown in Table I. This is also an expected situation since the magnetization is depending mainly on the contents of $\mathrm{Ni}$ atoms for investigated $\mathrm{Ni} / \mathrm{Al}$ multilayers. $H_{c}$ values were found as 30 , 89 , and 201 Oe for the films with Ni layer thicknesses of 10, 30, $70 \mathrm{~nm}$, respectively as shown in Table I. The $H_{c}$ value also increases with increase of Ni layer thickness and hence Ni content of the films. This is an anomalous situation regarding the relation between coercivity and non-magnetic content. It is stressed in [14] that an increase in non-magnetic content results in an increase in coercivity, unlike the present study. It can be understood that the change in $H_{c}$ values is also related to the change in the structural properties. The lowest $H_{c}$ value was obtained for the film with Ni layer thickness of $10 \mathrm{~nm}$ (for the highest $\mathrm{Al}$ content, 61 at.\% Al) (see Table I). This is most probably related to the surface similarity of the substrate and this multilayer (see Fig. 4). Namely, a growth which is compatible with the substrate surface may support the low coercivity. In addition, a vertical acicular morphology may lead to increase of $H_{c}$ 


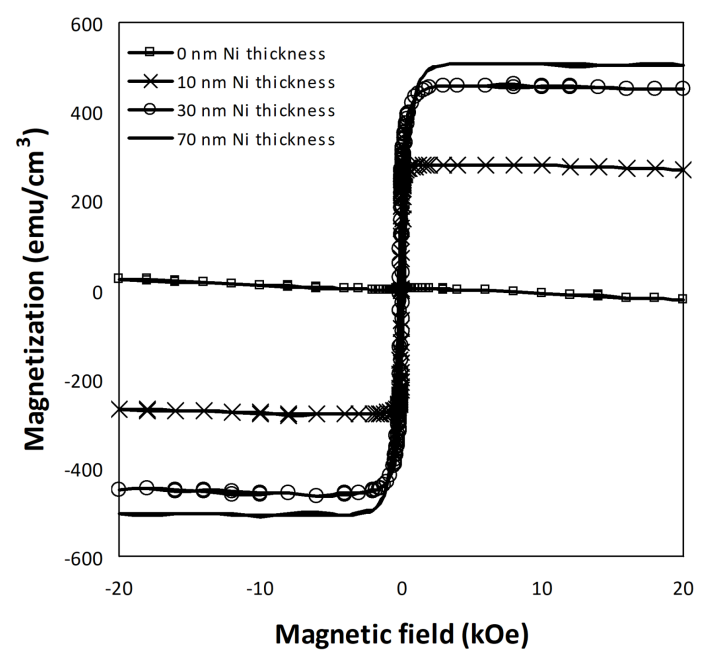

Fig. 5. Hysteresis loops of the $\mathrm{Ni} / \mathrm{Al}$ multilayers having different thicknesses of $\mathrm{Ni}$ layers.

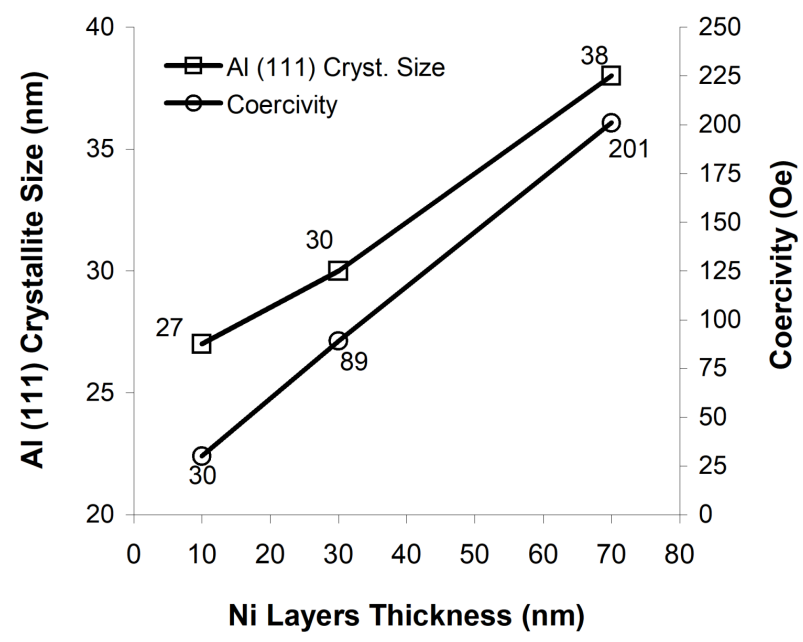

Fig. 6. Size of $\mathrm{Al}(111)$ crystallite and $H_{c}$ values depending on the thickness of Ni layers.

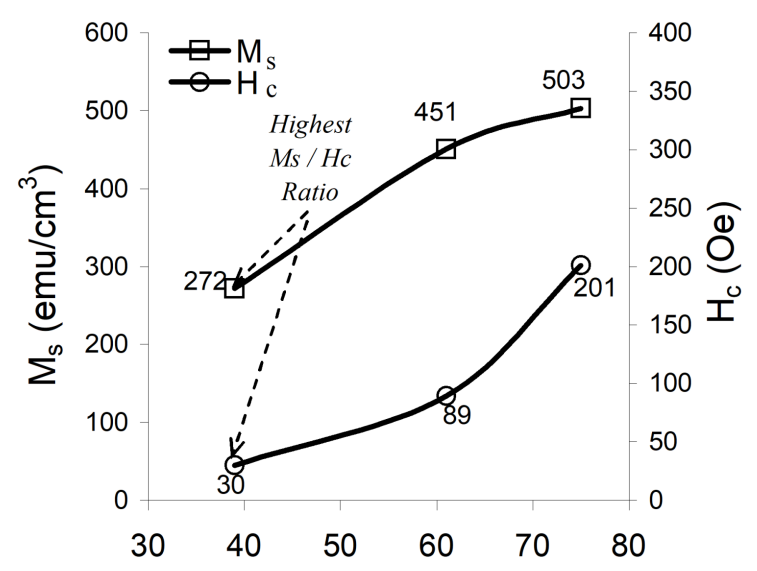

Ni content of the films (at.\%)

Fig. 7. $\quad M_{s}$ and $H_{c}$ values depending on Ni contents of the $\mathrm{Ni} / \mathrm{Al}$ multilayers. values. As stated in study [16] which investigated the hollow fibers with high $M_{s}$ and while comparatively low $H_{c}$, the $H_{c}$ is mainly affected by the surface morphology. It was concluded in the present study that the irregular structure of acicular morphology and relatively high size of $\mathrm{Al} \mathrm{fcc} \mathrm{(111)} \mathrm{crystallite} \mathrm{enhance} \mathrm{the} \mathrm{increase}$ in $H_{c}$ values as found in $\mathrm{Ni} / \mathrm{Al}$ multilayer with $\mathrm{Ni}$ layers thickness of $70 \mathrm{~nm}$. As clearly seen in Fig. 6, the change in the size of $\mathrm{Al}$ fcc (111) crystallite is compatible with the change in $H_{c}$ values when the thickness of $\mathrm{Ni}$ layers increases. Besides, it was calculated that $M_{s} / H_{c}$ value gradually decreased when the thickness of $\mathrm{Ni}$ layers increased. The multilayer with Ni layer thickness of $10 \mathrm{~nm}$ has the highest $M_{s} / H_{c}$ ratio among the films produced as shown in Fig. 7. This causes relatively less hysteresis losses together with relatively high saturation flux density in the materials in comparison with the others. Hence, it leads to more effective magnetic materials for technological write head applications $[14,15]$.

\section{Conclusions}

$\mathrm{Ni} / \mathrm{Al}$ multilayers were studied to detect the deposition parameters of optimum magnetic properties for their potential use as write head materials in a hard disk drive. The films were obtained by considering different thicknesses of magnetic layers with the sputtering technique. For all films, atomic Ni contents are compatible with the increasing thickness of Ni layers. The fcc structure was detected for all multilayers. The surface changed from an uneven and rough structure to an acicular and relatively smooth morphology for increasing Ni layer thickness from $0 \mathrm{~nm}$ to $70 \mathrm{~nm}$. A transition morphology between these morphologies was observed for the Ni layer thickness of $10 \mathrm{~nm}$ and this morphology was similar to that of the substrate, unlike the other morphologies. $M_{s}$ values were proportional to the atomic Ni content and $M_{s}$ and $H_{c}$ values increased with the increase of $\mathrm{Ni}$ layer thickness. It was found that a film surface which is similar to substrate surface may be responsible for low $H_{c}$ values, whereas an irregular acicular morphology and high size of Al fcc (111) crystallite may cause an increase in $H_{c}$ values. The lowest $H_{c}$ value and the highest $M_{s} / H_{c}$ ratio were obtained for the film with $\mathrm{Ni}$ layer thickness of $10 \mathrm{~nm}$. Therefore, among the investigated multilayers, the optimum magnetic properties were obtained for the film with Ni layer thickness of $10 \mathrm{~nm}$, i.e., $8[\mathrm{Ni}(10 \mathrm{~nm}) / \mathrm{Al}(10 \mathrm{~nm})]$. It is concluded that the deposition parameters of this film can be considered to obtain more effective materials for technological write head applications.

\section{Acknowledgments}

This study was financially supported by the Karamanoğlu Mehmetbey University under Grant no 17-M15, and by the State Planning Organization/Turkey under Grant no. 2005K120170 for Sputtering and the VSM systems. The authors would like to thank Hilal Kuru and Mehmet Uçkun for their contributions during the 
film production and measurements. The authors are also grateful to the Karamanoğlu Mehmetbey University/Karaman for the AFM imaging and the XRD measurements, and Selçuk University/Konya for the EDX measurements and the SEM images.

\section{References}

[1] H. Kockar, M. Alper, T. Sahin, O. Karaagac, J. Magn. Magn. Mater. 322, 1095 (2010).

[2] Y.S. Yu, Hai-Bo Li, W.L. Li, Mei Liu, Yu-Mei Zhang, W.D. Fei, J. Magn. Magn. Mater. 322, 1770 (2010).

[3] R.S. Liu, S.C. Chang, I. Baginskiy, S.F. Hu, C.Y. Huang, Pramana J. Phys. 67, 85 (2006).

[4] M. Chen, P.C. Searson, C.L. Chien, J. Appl. Phys. 93, 8253 (2003).

[5] P.C. Andricacos, N. Robertson, IBM J. Res. Developm. 42, 671 (1998).

[6] S.W. Kuk, H.J. Ryu, J. Yu, J. Alloys Comp. 589 455 (2014).

[7] J. Noro, A.S. Ramos, M.T. Vieira, Intermetallics 16, 1061 (2008).

[8] S. Simões, F. Viana, A.S. Ramos, M.T. Vieira, M.F. Vieira, Intermetallics 19, 350 (2011).

[9] S. Tixier, P. Böni, H. Van Swygenhoven, Thin Solid Films 342, 188 (1999).

[10] S.S. Kang, J.W. Feng, G.J. Jin, M. Lu, X.N. Xu, A. Hu, S.S. Jiang, H. Xia, J. Magn. Magn. Mater. 166, 277 (1997).

[11] G.R. Pattanaik, D.K. Pandya, S.C. Kashyap, Thin Solid Films 433, 247 (2003).

[12] H. Kockar, M. Alper, H. Kuru, T. Meydan, J. Magn. Magn. Mater. 304, e736 (2006).

[13] H. Kuru, M. Alper, H. Kockar, J. Optoelectron. Adv. Mater. Symp. 1, 432 (2009).

[14] D. Jiles, Introduction to Magnetism and Magnetic Materials, Chapman and Hall, London 1991.
[15] T. Osaka, M. Takai, K. Hayashi, K. Ohashi, M. Saito, K. Yamada, Nature 392, 796 (1998).

[16] G.-Fang Liu, Z.-Dong Zhang, F. Dang, C.-Bing Cheng, C.-Xin Hou, S.-Da Liu, J. Magn. Magn. Mater. 412, 55 (2016).

[17] N.X. Sun, S.X. Wang, IEEE Trans. Magn. 36, 2506 (2000).

[18] X. Liu, G. Zangari, in: Magnetic Materials, Processes, and Devices VI: Applications to Storage and Microelectromechanical Systems (MEMS): Proc. Int. Symp., Eds. S. Krongelb, L.T. Romankiw, J.W. Chang, W. Schwarzacher, C.H. Ahn, Electrochemical Society, Pennington (NJ) 2001, p. 211.

[19] I.Z. Rahman, M.V. Khaddem-Mousavi, A.A. Gandhi, T.F. Lynch, M.A. Rahman, J. Phys. Conf. Series 61, 523 (2007).

[20] B.B. Straumal, A.A. Mazilkin, S.G. Protasova, S.V. Dobatkin, A.O. Rodin, B. Baretzky, D. Goll, G. Schütz, Mater. Sci. Eng. A 503, 185 (2009).

[21] J.B. Yi, Y.Z. Zhou, J. Ding, G.M. Chow, Z.L. Dong, T. White, Xing Yu Gao, A.T.S. Wee, X.J. Yu, J. Magn. Magn. Mater. 284, 303 (2004).

[22] M. Swain, S. Singh, S. Basu, D. Bhattacharya, R.B. Tokas, M. Gupta, J. Alloys Comp. 631, 46 (2015).

[23] Z. Świątek, A. Gradys, Ł. Maj, J. Morgiel, K.W. Marszałek, R. Mania, M. Szlezynger, Acta Phys. Pol. A 130, 880 (2016).

[24] R.A. Mahesh, R. Jayaganthan, S. Prakash, V. Chawla, R. Chandra, Mater. Chem. Phys. 114, 629 (2009).

[25] P.Y. Li, H.M. Lu, S.C. Tang, X.K. Meng, J. Alloys Comp. 478, 240 (2009).

[26] R.Y. Zhang, I. Amlani, J. Baker, J. Tresek, R.K. Tsui, Nano Lett. 3, 731 (2003). 